\title{
Adjuvant breast cancer chemotherapy during late-trimester pregnancy: not quite a standard of care Richard J Epstein*
}

\author{
Address: Division of Haematology/Oncology, Department of Medicine, The University of Hong Kong, Pokfulam, Hong Kong \\ Email: Richard J Epstein* - repstein@ @ku.hk \\ * Corresponding author
}

Published: 30 May 2007

BMC Cancer 2007, 7:92 doi:10.1 |86/|47|-2407-7-92
Received: 28 September 2006

Accepted: 30 May 2007

This article is available from: http://www.biomedcentral.com/I47/-2407/7/92

(C) 2007 Epstein; licensee BioMed Central Ltd.

This is an Open Access article distributed under the terms of the Creative Commons Attribution License (http://creativecommons.org/licenses/by/2.0), which permits unrestricted use, distribution, and reproduction in any medium, provided the original work is properly cited.

\begin{abstract}
Background: Diagnosis of breast cancer during pregnancy was formerly considered an indication for abortion. The pendulum has since swung to the other extreme, with most reviews now rejecting termination while endorsing immediate anthracycline-based therapy for any pregnant patient beyond the first trimester. To assess the evidence for this radical change in thinking, a review of relevant studies in the fields of breast cancer chemotherapy, pregnancy, and drug safety was conducted.
\end{abstract}

Discussion: Accumulating evidence for the short-term safety of anthracycline-based chemotherapy during late-trimester pregnancy represents a clear advance over the traditional norm of therapeutic abortion. Nonetheless, the emerging orthodoxy favoring routine chemotherapy during gestation should continue to be questioned on several grounds: (I) the assumed difference in maternal survival accruing from chemotherapy administered earlier - i.e., during pregnancy, rather than after delivery - has not been quantified; (2) the added survival benefit of adjuvant cytotoxic therapy prescribed within the hormone-rich milieu of pregnancy remains presumptive, particularly for ER-positive disease; (3) the maternal survival benefit associated with modified adjuvant regimens (e.g., weekly schedules, omission of taxanes, etc.) has not been proven equivalent to standard (e.g., post-delivery) regimens; and (4) the long-term transplacental and transgenerational hazards of late-trimester chemotherapy are unknown.

Summary: Although an incrementally increased risk of cancer-specific mortality is impossible to exclude, mothers who place a high priority on the lifelong well-being of their progeny may be informed that deferring optimal chemotherapy until after delivery is still an option to consider, especially in ER-positive, node-negative and/or last-trimester disease.

\section{Background}

Immediate chemotherapy may be clearly indicated for pregnant breast cancer patients with unresectable primary tumors or metastatic presentations, whereas operable tumors raise a more complex conflict of interest: the mother is threatened directly by cancer recurrence and hence, indirectly, by any treatment compromise made on behalf of the fetus. Decisions made in this context tend to be less drastic for the mother than for the fetus, given that the latter has more life-years to lose, and faces health hazards that are wholly avoidable. This risk imbalance is worsened by the weaker advocacy position of the fetus, who tends not to be considered the primary 'client' in such oncologic scenarios. 


\section{Discussion}

Recent studies have emphasized the safety of adjuvant anthracycline-based drug therapy during the second and third trimesters [1-5]. The post-resection dilemma in latetrimester cases can thus be reduced to three choices: termination of pregnancy followed by state-of-the-art adjuvant treatment; continuation of pregnancy with immediate administration of modified chemotherapy regimens that typically lack antimetabolites [6,7], taxanes [2] and trastuzumab [8] due to safety uncertainties; or continuation of pregnancy with optimal chemotherapy given after delivery (Figure 1). Exclusive prioritization of decision-making towards the physical health of the mother favors termination followed by standard treatment, whereas prioritization towards the physical health of the fetus favors deferral of all nonsurgical treatments until after delivery. Many oncologists now see the option of second- and third-trimester cytotoxic therapy (hereinafter termed gestational chemotherapy) as a happy medium between these conservative and pro-active management positions, not least because of carefully-worded endorsements of anthracycline-based therapies as capable of being given with "minimal complications of labor and delivery" [1] or "minimal risk to the fetus" [2].
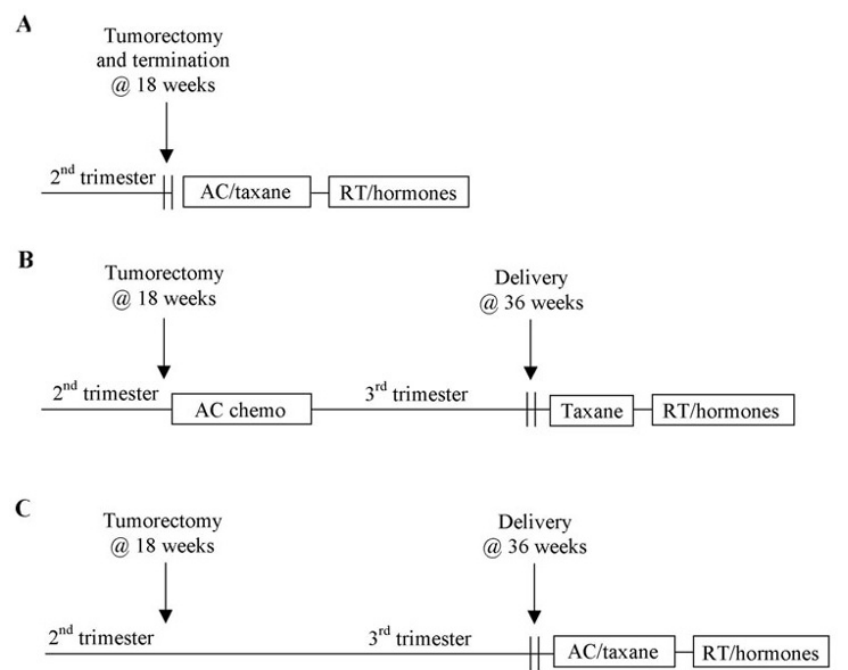

D

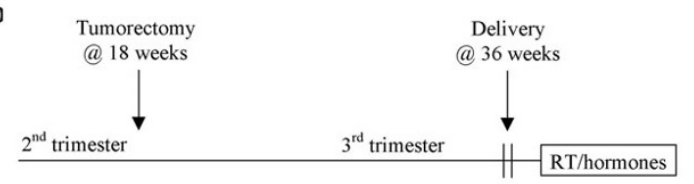

Figure I

Schematic representation of patient choices for adjuvant therapies in resectable primary breast cancer diagnosed in the second or third trimesters. $A$, Immediate termination; $B$, Chemotherapy during pregnancy; $C$, Chemotherapy after pregnancy; $D$, No chemotherapy.

\section{Therapeutic delay}

A central belief underlying the new enthusiasm for gestational chemotherapy is that delay of adjuvant cancer treatment is substantially deleterious to maternal outcomes. Taken to extremes, this assumption must be valid: if adjuvant treatment is delayed until metastases appear, the opportunity for cure has been lost. Such logic likewise supports the utility of therapeutic abortion which, uniquely, permits full deployment of all adjuvant modalities according to standard time-schedules. Relevant to this, however, no survival benefit attributable to therapeutic abortion has yet been proven [5], despite the fact that this option enables the most standard adjuvant therapy scheduling.

At present, there are no controlled data defining the extent to which a less extreme delay in the initiation of adjuvant therapy impairs overall survival outcomes. Retrospective studies have indicated that adjuvant chemotherapy delays of up to three months have no discernible effect on prognosis $[9,10]$; only in very advanced disease has delay in initiating adjuvant chemotherapy been associated with any impairment of disease-free survival [11], though other groups have failed to demonstrate impaired overall survival in any patient subset [12]. Using a model that quantifies risk increments in patients deferring breast cancer chemotherapy until after delivery, Nettleton et al estimated a modest $1.5-4.0 \%$ increased risk of transforming from axillary node-negative to -positive [13] in late-trimester patients, assuming a typical 10-12 week delay [14]. A large retrospective review of premenopausal patients indicated that only patients with ER-absent tumors are likely to benefit from early initiation of adjuvant chemotherapy [15].

\section{Therapeutic benefit}

While it is reasonable to believe that gestational chemotherapy confers survival benefits similar to those apparent in overviews of nonpregnant patients receiving conventional chemotherapy [16], such overviews only calculate average effects, and should not be extrapolated to patient subsets affected by qualitative interactions [17]. Pregnancy represents exactly such an interaction: dramatic changes of mammary gland gene expression are induced by the presence of the fetus [18], reflecting corresponding changes in the tumor microenvironment. Breast cancer survival outcomes vary inversely with diagnostic proximity to earlier pregnancy $[19,20]$, raising the possibility of biological resistance to adjuvant treatments. Since the benefit of chemotherapy tends to be lower for hormonedriven tumors in both the adjuvant [21] and neoadjuvant settings [22-24], and appears similar to that of ovarian suppression in premenopausal women with hormonedependent disease $[25,26]$, the question arises: for pregnant patients whose tumors express some hormone recep- 
tors, will adjuvant chemotherapy given "early" in the hormone-rich pregnancy environment necessarily be more effective than similar chemotherapy given after delivery; or could the opposite be the case?

A further worry raised by the vogue for gestational chemotherapy is the possibility that suboptimal regimens may be delivered, albeit with good intentions; in the worst of all possible worlds, such regimens could imperil the fetus without benefiting the mother. For example, Peccatori et al treated pregnant patients using weekly epirubicin 30$50 \mathrm{mg} / \mathrm{m}^{2}$ with the aim of maximizing therapeutic effect while minimizing fetal drug exposure [27]. However, the adjuvant efficacy of such customized regimens - whether in pregnant or non-pregnant patients - is simply not known, though it is accepted that "low-dose" chemotherapy regimens are less effective. Other modifications of standard regimens - e.g., exclusion of antimetabolites and/or taxanes, lower dose-intensity and/or dose-density, or withholding of the humanized antibody trastuzumab are popular in this setting, raising the question: is the administration of such 'modified' regimens during pregnancy aimed at treating the patient or the doctor? If a pregnant breast cancer patient does not receive chemotherapy of similar efficacy to that received by nonpregnant patients, should it be assumed that this deficiency will be rectified in the post-partum period - or would it be better to defer the entire treatment regimen until after delivery, at which time a more concentrated and intensive approach could plausibly improve survival benefits?

\section{Therapeutic safety}

The usual endpoints that have been used to determine the fetal 'safety' of late-trimester chemotherapy include congenital malformations, developmental milestones and pediatric tumor rate. Indeed, the literature is replete with series $[28,29]$ and case reports [30-32] of 'safe' treatment anecdotes where no obvious fetal malformation was documented following gestational chemotherapy. Yet as reassuring as these negative reports sound, they may not reflect the actual toxicity of late-trimester chemotherapy. Intrauterine growth retardation, miscarriages, stillbirths, pre-eclampsia and prematurity are increased in pregnancies involving cytotoxic treatment [33], yet are not ranked as malformations or teratogenicity. As listed in Table 1, more subtle long-term deficits in transplacentally-exposed progeny - such as reduced fertility, fine cognitive deficiencies, more frequent adult solid tumors, diminished longevity, or transgenerational carcinogenesis - may become apparent in "chemo babies" only after long-term surveillance [34].

A further safety-related concern is that a future pregnancy is possible, but not guaranteed. The summative risks of chemotherapy-induced infertility (say, 20\%), early meta-
Table I: Expected vs. non-expected positive endpoints for gestational exposure to cytotoxic drugs.

\section{Expected effects of transplacental mutagens in late-} trimester pregnancies

\begin{tabular}{|c|c|}
\hline Expected to be normal & Expected to be abnormal \\
\hline Congenital malformation rate & Abortion rate \\
\hline Postnatal apgar indices & Prematurity, stillbirth \\
\hline Neurologic milestones & Birth weight \\
\hline Infant sexual/genital development & Adult fertility \\
\hline Pediatric cancer rate & Adult cancer rate \\
\hline $\begin{array}{l}\text { Transgenerational malformation } \\
\text { rate }\end{array}$ & Transgenerational cancer rate \\
\hline Short-term cardiovascular function & $\begin{array}{l}\text { Long-term cardiovascular } \\
\text { function }\end{array}$ \\
\hline Learning ability & Longevity \\
\hline
\end{tabular}

static relapse (say, 20\%) or marital problems (say, 10\%) might be expected to reduce the certainty of having another baby, keeping in mind that the duration of any adjuvant hormonal therapy is likely to be five years or longer. Although it is difficult to quantify the relative net fertility outcomes of early vs. late chemotherapy in this context, it is certainly arguable that the fetus of a pregnant breast cancer patient may be, if anything, more precious to the mother than the average pregnancy, given the uncertain prognoses for both maternal survival and fecundity.

Moreover, patients may believe that the most painful choice - in this case, abortion, which is chosen in up to $50 \%$ of cases in many international series [35] - must be the best [36]. Clinicians aware of the anxieties facing the patient may feel obliged to offer active intervention ("at least we're doing something"), unintentionally biasing informed consent [37]. Patient acceptance of gestational chemotherapy may likewise have more to do with cultural norms of cooperation and punishment [38] than with logical consideration of all options. These concerns support reservations expressed by Barthelmes et al [39], Pautier et al [40] and Mathieu et al [41] about the trend towards routine immediate adjuvant chemotherapy for late-trimester breast cancer patients.

\section{Summary}

Oncologists may be less familiar than obstetricians with the ethical complexities confronting pregnant patients. Management of cancer in pregnancy is complicated by the tendencies of clinicians to equate (maternal) risk with (maternal plus fetal) benefit, to assume that immediacy of action is always best, to hold the interests of the 'client' (mother) above those of any third party (fetus), and to imply that lack of proven danger equals safety. Basing standard recommendations on such convictions is tempt- 
ing, but firmer knowledge of gestational breast cancer biology, measured therapeutic benefits, and longer-term toxicity data is needed before any such standard can be scientifically endorsed [42]. In the meantime, the debate will continue as to whether chemotherapy should be presumed 'innocent until proven guilty' or 'guilty until proven innocent': although the Hippocratic ethical maxim "First, do no harm" favors the latter from the viewpoint of the fetus, an assumption of gestational chemotherapy efficacy will favor the former from the viewpoint of the mother.

The inconvenient truth remains that gestational chemotherapy has not yet been proven to have net benefits (long-term maternal survival increments minus long-term fetal toxicities) exceeding those of delayed chemotherapy. Equally, however, there remains insufficient data to claim that delayed chemotherapy should be standard, and the issue is likely to remain unresolved. Nonetheless, deferral of chemotherapy to the post-partum period remains a valid and defensible option for oncologists to invite selected late-trimester breast cancer patients - e.g., those with hormone receptor-positive disease, node-negative staging, and/or no more than 12 weeks until delivery - to consider.

\section{Abbreviations}

Nil

\section{Competing interests}

The author(s) declare that they have no competing interests.

\section{Acknowledgements}

The author thanks the reviewers for constructive comments, Dr Polly Cheung for helpful discussions, and Professor Raymond Liang for support.

\section{References}

I. Berry DL, Theriault RL, Holmes FA, Parisi VM, Booser DJ, Singletary SE, Buzdar AU, Hortobagyi GN: Management of breast cancer during pregnancy using a standardized protocol. J Clin Oncol 1999, I 7(3):855-86|.

2. Loibl S, von Minckwitz G, Gwyn K, Ellis P, Blohmer JU, Schlegelberger B, Keller M, Harder S, Theriault RL, Crivellari D, Klingebiel T, Louwen F, Kaufmann M: Breast carcinoma during pregnancy. International recommendations from an expert meeting. Cancer 2006, I 06(2):237-246.

3. Woo JC, Yu T, Hurd TC: Breast cancer in pregnancy: a literature review. Arch Surg 2003, I38(I):91-8; discussion 99.

4. Ring AE, Smith IE, Jones A, Shannon C, Galani E, Ellis PA: Chemotherapy for breast cancer during pregnancy: an I8-year experience from five London teaching hospitals. J Clin Oncol 2005, 23( I 8):4| 92-4I97.

5. Gwyn KM, Theriault RL: Breast cancer during pregnancy. Curr Treat Options Oncol 2000, I(3):239-243.

6. Bawle EV, Conard JV, Weiss L: Adult and two children with fetal methotrexate syndrome. Teratology 1998, 57(2):5 I-55.

7. Paskulin GA, Gazzola Zen PR, de Camargo Pinto LL, Rosa R, Graziadio C: Combined chemotherapy and teratogenicity. Birth Defects Res A Clin Mol Teratol 2005, 73(9):634-637.
8. Watson WJ: Herceptin (trastuzumab) therapy during pregnancy: association with reversible anhydramnios. Obstet Gyne$\mathrm{col}$ 2005, I 05(3):642-643.

9. Cold S, During M, Ewertz M, Knoop A, Moller S: Does timing of adjuvant chemotherapy influence the prognosis after early breast cancer? Results of the Danish Breast Cancer Cooperative Group (DBCG). Br J Cancer 2005, 93(6):627-632.

10. Lohrisch C, Paltiel C, Gelmon K, Speers C, Taylor S, Barnett J, Olivotto IA: Impact on survival of time from definitive surgery to initiation of adjuvant chemotherapy for early-stage breast cancer. J Clin Oncol 2006, 24(30):4888-4894.

II. Buzdar AU, Smith TL, Powell KC, Blumenschein GR, Gehan EA: Effect of timing of initiation of adjuvant chemotherapy on disease-free survival in breast cancer. Breast Cancer Res Treat 1982, 2(2): 163-169.

12. Shannon C, Ashley S, Smith IE: Does timing of adjuvant chemotherapy for early breast cancer influence survival? J Clin Oncol 2003, 2 I (20):3792-3797.

13. Nettleton J, Long J, Kuban D, Wu R, Shaefffer J, El-Mahdi A: Breast cancer during pregnancy: quantifying the risk of treatment delay. Obstet Gynecol 1996, 87(3):4I4-418.

14. Giacalone PL, Laffargue F, Benos P: Chemotherapy for breast carcinoma during pregnancy: A French national survey. Cancer 1999, 86(I I):2266-2272.

15. Colleoni M, Bonetti M, Coates AS, Castiglione-Gertsch M, Gelber RD, Price K, Rudenstam CM, Lindtner J, Collins J, Thurlimann B, Holmberg S, Veronesi A, Marini G, Goldhirsch A: Early start of adjuvant chemotherapy may improve treatment outcome for premenopausal breast cancer patients with tumors not expressing estrogen receptors. The International Breast Cancer Study Group. J Clin Oncol 2000, I 8(3):584-590.

16. Cole BF, Gelber RD, Gelber S, Coates AS, Goldhirsch A: Polychemotherapy for early breast cancer: an overview of the randomised clinical trials with quality-adjusted survival analysis. Lancet 200I, 358(9278):277-286.

17. Wittes RE: Problems in the medical interpretation of overviews. Stat Med 1987, 6(3):269-280.

18. Verlinden I, Gungor N, Wouters K, Janssens J, Raus J, Michiels L: Parity-induced changes in global gene expression in the human mammary gland. Eur J Cancer Prev 2005, I 4(2): I 29- I 37.

19. Phillips KA, Milne RL, Friedlander ML, Jenkins MA, McCredie MR, Giles GG, Hopper JL: Prognosis of premenopausal breast cancer and childbirth prior to diagnosis. J Clin Oncol 2004, 22(4):699-705.

20. Rosenberg L, Thalib L, Adami HO, Hall P: Childbirth and breast cancer prognosis. Int J Cancer 2004, I I I(5):772-776.

21. Regan MM, Gelber RD: Predicting response to systemic treatments: learning from the past to plan for the future. Breast 2005, I 4(6):582-593.

22. Ring AE, Smith IE, Ashley S, Fulford LG, Lakhani SR: Oestrogen receptor status, pathological complete response and prognosis in patients receiving neoadjuvant chemotherapy for early breast cancer. Br J Cancer 2004, 9 I (1 2):2012-2017.

23. Manna Edel F, Teixeira LC, Alvarenga M: Association between immunohistochemical expression of topoisomerase Ilalpha, HER2 and hormone receptors and response to primary chemotherapy in breast cancer. Tumori 2006, 92(3):222-229.

24. Colleoni M, Viale G, Zahrieh D, Pruneri G, Gentilini O, Veronesi P, Gelber RD, Curigliano G, Torrisi R, Luini A, Intra M, Galimberti V, Renne G, Nole F, Peruzzotti G, Goldhirsch A: Chemotherapy is more effective in patients with breast cancer not expressing steroid hormone receptors: a study of preoperative treatment. Clin Cancer Res 2004, I (1 (9):6622-6628.

25. Aebi S: Special issues related to the adjuvant therapy in very young women. Breast 2005, I 4(6):594-599.

26. Roche H, Kerbrat P, Bonneterre J, Fargeot P, Fumoleau P, Monnier A, Clavere P, Goudier MJ, Chollet P, Guastalla JP, Serin D: Complete hormonal blockade versus epirubicin-based chemotherapy in premenopausal, one to three node-positive, and hormone-receptor positive, early breast cancer patients: 7-year follow-up results of French Adjuvant Study Group 06 randomised trial. Ann Oncol 2006, I7(8): | $22 \mid-1227$.

27. Peccatori F, Martinelli G, Gentilini O, Goldhirsch A: Chemotherapy during pregnancy: what is really safe? Lancet Oncol 2004, 5(7):398. 
28. Aviles $\mathrm{A}, \mathrm{Niz}$ J: Long-term follow-up of children born to mothers with acute leukemia during pregnancy. Med Pediatr Oncol 1988, 16(1):3-6.

29. Aviles A, Diaz-Maqueo JC, Talavera A, Guzman R, Garcia EL: Growth and development of children of mothers treated with chemotherapy during pregnancy: current status of $\mathbf{4 3}$ children. Am J Hematol I99I, 36(4):243-248.

30. Fanale MA, Uyei AR, Theriault RL, Adam K, Thompson RA: Treatment of metastatic breast cancer with trastuzumab and vinorelbine during pregnancy. Clin Breast Cancer 2005, 6(4):354-356

31. Nieto Y, Santisteban M, Aramendia JM, Fernandez-Hidalgo O, GarciaManero M, Lopez G: Docetaxel administered during pregnancy for inflammatory breast carcinoma. Clin Breast Cancer 2006, 6(6):533-534.

32. Andreadis C, Charalampidou M, Diamantopoulos N, Chouchos N, Mouratidou D: Combined chemotherapy and radiotherapy during conception and first two trimesters of gestation in a woman with metastatic breast cancer. Gynecol Oncol 2004, 95(I):252-255.

33. Zemlickis D, Lishner M, Degendorfer P, Panzarella T, Sutcliffe SB, Koren G: Fetal outcome after in utero exposure to cancer chemotherapy. Arch Intern Med I992, I 52(3):573-576.

34. Byrne J: Long-term genetic and reproductive effects of ionizing radiation and chemotherapeutic agents on cancer patients and their offspring. Teratology 1999, 59(4):210-215.

35. Ibrahim EM, Ezzat AA, Baloush A, Hussain ZH, Mohammed GH: Pregnancy-associated breast cancer: a case-control study in a young population with a high-fertility rate. Med Oncol 2000 , I 7(4):293-300.

36. Tomich PL, Helgeson VS: Is finding something good in the bad always good? Benefit finding among women with breast cancer. Health Psychol 2004, 23(I):16-23.

37. Hedgecoe A: 'At the point at which you can do something about it, then it becomes more relevant': informed consent in the pharmacogenetic clinic. Soc Sci Med 2005, 6I(6): $|20|-|2| 0$.

38. Henrich J, McElreath R, Barr A, Ensminger J, Barrett C, Bolyanatz A, Cardenas JC, Gurven M, Gwako E, Henrich N, Lesorogol C, Marlowe F, Tracer D, Ziker J: Costly punishment across human societies. Science 2006, 3 I 2(578I): 1767-I770.

39. Barthelmes L, Davidson LA, Gaffney C, Gateley CA: Pregnancy and breast cancer. Bmj 2005, 330(7504): 1375-1378.

40. Pautier P, Lhomme C, Morice P: Cancer and pregnancy: the medical oncologist's point of view. I Gynecol Obstet Biol Reprod (Paris) 2004, 33(I Suppl):S23-8.

41. Mathieu E, Merviel P, Antoine JM, Uzan S: Cancer and Pregnancy: the point of view of the obstetrician. Bull Cancer 2002, 89(9):758-764.

42. O'Donnell JL, Smyth D, Frampton C: Prioritizing health-care funding. Intern Med J 2005, 35(7):409-4I2.

\section{Pre-publication history}

The pre-publication history for this paper can be accessed here:

http://www.biomedcentral.com/1471-2407/7/92/prepub

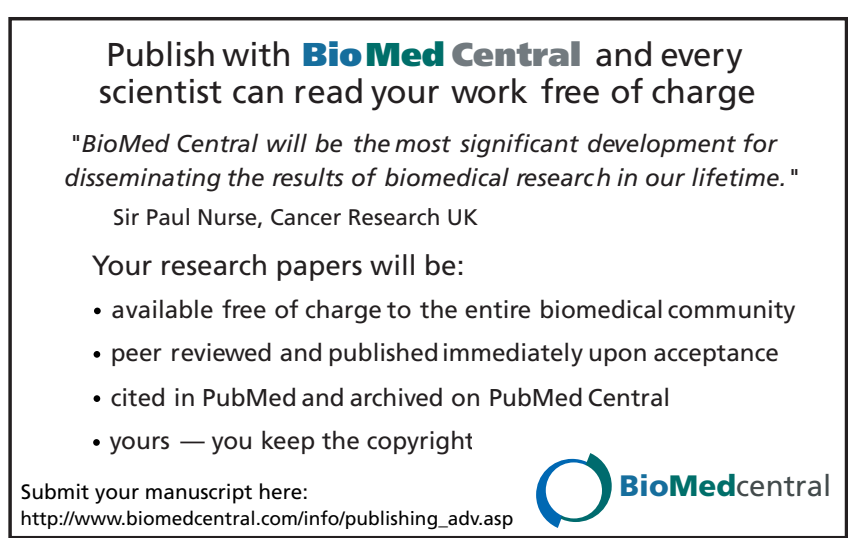

